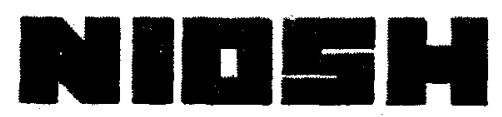

criteria for a recommended standard .... . occupational exposure to

\title{
ETHYLENE DIBROMIDE
}
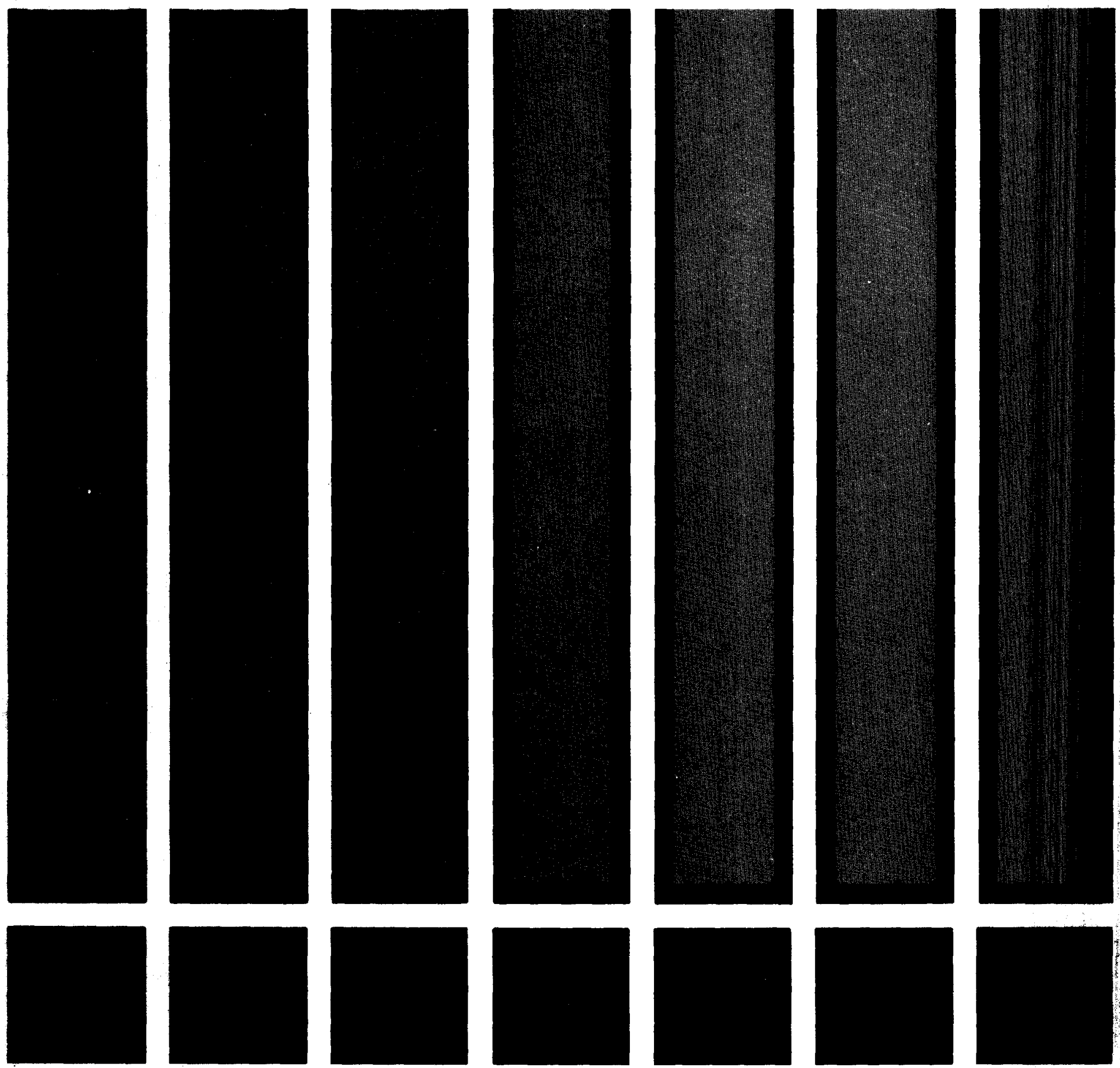

U.8. DEPARTMENT OF HEALTH, EDUCATION, AND WELFARE

Public Health Service Center for Disease Control

National Institute for Occupational Safety and Health 


\section{criteria for a recommended standard....}

\section{OCCUPATIONAL EXPOSURE TO}

\section{ETHYLENE DIBROMIDE}

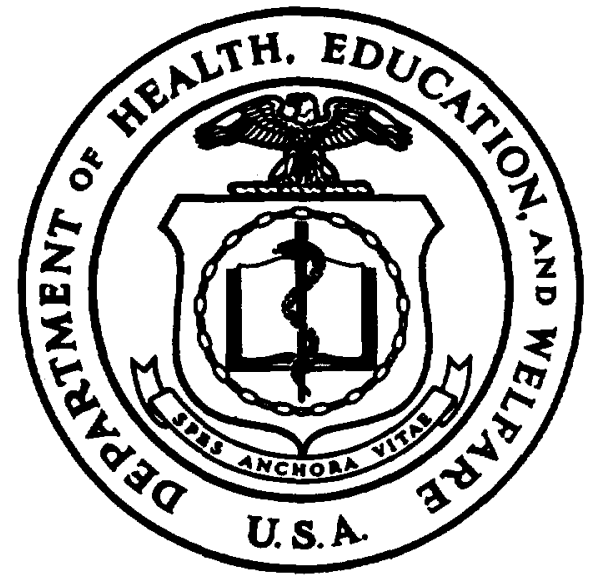

U.S. DEPARTMENT OF HEALTH, EDUCATION, AND WELFARE

Public Health Service

Center for Disease Control

National Institute for Occupational Safety and Health

AUGUST 1977

For sale by the Superintendent of Documents, U.S. Government

Printing Office, Washington, D.C. 20402 
DHEW (NIOSH) Publication No. 77-221 
PREFACE

The Occupational Safety and Health Act of 1970 emphasizes the need for standards to protect the health and safety of workers exposed to an ever-increasing number of potential hazards at their workplace. The National Institute for Occupational Safety and Health has projected a formal system of research, with priorities determined on the basis of specified indices, to provide relevant data from which valid criteria for effective standards can be derived. Recommended standards for occupational exposure, which are the result of this work, are based on the health effects of exposure. The Secretary of Labor will weigh these recommendations along with other considerations such as feasibility and means of implementation in developing regulatory standards.

It is intended to present successive reports as research and epidemiologic studies are completed and as sampling and analytical methods are developed. Criteria and standards will be reviewed periodically to ensure continuing protection of the worker.

I am pleased to acknowledge the contributions to this report on ethylene dibromide by members of the NIOSH staff and the valuable constructive comments by the Review Consultants on Ethylene Dibromide, by the ad hoc committees of the Society for Occupational and Environmental Health and the American Industrial Hygiene Association, and by Robert $B$. 
O'Connor, M.D., NIOSH consultant in occupational medicine. The NIOSH recommendations for standards are not necessarily a consensus of all the consultants and professional societies that reviewed this criteria document on ethylene dibromide. A list of Review Consultants appears on page vi.

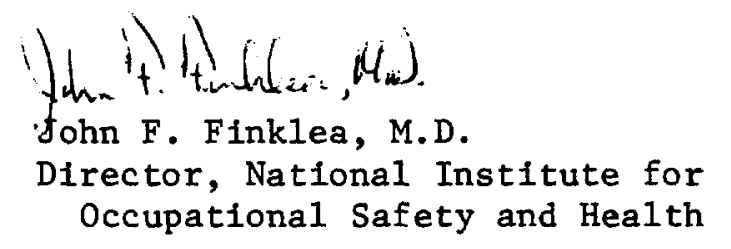


Theodore J. Elias

Chief, Occupational Health Diviston

Community Health Services

County of Los Angeles

Los Angeles, California 90012

David B. Johns, M.D.

Medical Director

Dow Chemical USA

Midland, Michigan 48640

H. Eldon Sutton, Ph.D.

Vice President for Research

University of Texas

Austin, Texas 78712

Gary Ter Haar, Ph.D.

Acting Director, Toxicology and

Industrial Hygiene Department

Ethy1 Corporation

Baton Rouge, Louisiana 70801

James G. Wilson, Ph.D.

Director of Pathologic Embryology

Institute of Developmental Research

Children's Hospital Research Foundation

Cincinnati, Ohio 45229 
The Division of Criteria Documentation and Standards Development, National Institute for Occupational Safety and Health, had primary responsibility for development of the criteria and recommended standard for ethylene dibromide. Gamil Debbas, Ph.D., was the criteria manager for the major development of the document and Jerry LR Chandler, Ph.D., served as criteria manager during the latter stages. SRI International developed the basic information for consideration by NIOSH staff and consultants under contract No. CDC-99-74-31.

The Division review of this document was provided by Douglas L. Smith, Ph.D. (Chairman), J. Henry Wills, Ph.D., Paul E. Caplan, with Harry B. Plotnick, Ph.D. (Division of Biomedical and Behavioral Sciences), Robert A. Rinsky, (Division of Surveillance, Hazard Evaluations, and Field Studies), and Clara H. Williams, Ph.D.

The views expressed and conclusions reached in this document, together with the recommendations for a standard, are those of NIOSH, after review of the evidence and consideration of the comments of reviewers. These views and conclusions are not necessarily those of the consultants, other federal agencies, and professional societies that reviewed the document, or of the contractor. 
CRITERIA DOCUMENT:

RECOMMENDATIONS FOR AN OCCUPATIONAL

EXPOSURE STANDARD FOR ETHYLENE DIBROMIDE

Table of Contents

$\underline{\text { Page }}$

PREFACE

iii

REVIEW CONSULTANTS

vi

I. RECOMMENDATIONS FOR AN ETHYLENE DIBROMIDE STANDARD 1

Section 1 - Environmental (Workplace Air) 2

Section 2 - Medical 3

Section 3 - Labeling and Posting 5

Section 4 - Personal Protective Equipment and Clothing 6

Section 5 - Informing Employees of Hazards from 9 Ethylene Dibromide

Section 6 - Work Practices 11

Section 7 - Sanitation Practices 18

Section 8 - Monitoring and Recordkeeping Requirements 19

II. INTRODUCTION 21

III. BIOLOGIC EFFECTS OF EXPOSURE 23

Extent of Exposure $\quad 25$

Historical Reports $\quad 27$

Effects on Humans $\quad 27$

Epidemiologic Studies $\quad 34$

Animal Toxicity 38

Carcinogenic, Mutagenic, and Teratogenic Studies $\quad 82$

Correlation of Exposure and Effect 96

$\begin{array}{ll}\text { Carcinogenicity, Mutagenicity, Teratogenicity, and } & 105 \\ \text { Effects on Reproduction } & \end{array}$

Summary Tables of Exposure and Effect 113

IV. ENVIRONMENTAL DATA AND ENGINEERING CONTROLS 121

Environmental Concentrations $\quad 121$

Sampling and Analytical Methods 130

$\begin{array}{ll}\text { Engineering Controls } & 135\end{array}$

$\begin{array}{ll}\text { V. WORK PRACTICES } & 136\end{array}$ 
Table of Contents (Continued)

Page

VI. DEVELOPMENT OF STANDARD 143

Basis for Previous Standards 143

Basis for the Recommended Standard 146

$\begin{array}{ll}\text { VII. RESEARCH NEEDS } & 162\end{array}$

$\begin{array}{lll}\text { VIII. REFERENCES } & 167\end{array}$

IX. APPENDIX I - Method for Sampling Ethylene Dibromide in Air 177

X. APPENDIX II - Analytical Method for Ethylene Dibromide 182

XI. APPENDIX III - Material Safety Data Sheet 193

XII. TABLES AND FIGURE 203 


\section{RECOMMENDATIONS FOR AN ETHYLENE DIBROMIDE STANDARD}

The National Institute for Occupational Safety and Health (NIOSH) recommends that employee exposure to ethylene dibromide in the workplace be controlled by adherence to the following sections. The standard is designed to protect the health and provide for the safety of employees for up to a 10-hour workday, 40-hour workweek, over a working lifetime. Compliance with all sections of the standard should prevent adverse effects of ethylene dibromide on the health of employees and provide for their safety. Techniques recommended in the standard are valid, reproducible, and avallable to industry and government agencies. Sufficient technology exists to permit compliance with the recommended standard. Although NIOSH considers the workplace environmental limit to be a safe level based on current information, the employer should regard it as the upper boundary of exposure and make every effort to maintain the exposure as low as is technically feasible. The criteria and standard will be subject to review and revision as necessary.

The possible health effects of employees chronically exposed to ethylene dibromide may include the induction of cancers, malformations and heritable changes in offspring, and sterility. Ethylene dibromide may also cause adverse effects to the liver, kidneys, heart, and other internal organs and systems. Direct contact of the skin with ethylene dibromide may induce chemical burns as well as systemic effects, and ingestion of ethylene dibromide may damage internal organ systems, or even be fatal. The alkylation of cellular constituents, including the genetic material, deoxyribonucleic acid (DNA), is the most plausible molecular basis for the 
induction of adverse effects after exposure to ethylene dibromide.

These criteria and the recommended standard apply to occupational exposure of workers to the brominated hydrocarbon $\mathrm{BrCH} 2 \mathrm{CH} 2 \mathrm{Br}$, hereinafter referred to as "ethylene dibromide." Synonyms for ethylene dibromide include ethylene bromide, dibromoethane, sym-dibromoethane, 1,2dibromoethane, glycol dibromide, and EDB. The major uses of ethylene dibromide are as an additive to leaded gasoline and as a component of fumigants .

"Occupational exposure to ethylene dibromide" is defined as work in any establishment where ethylene dibromide is manufactured, blended, stored, used, handled, or otherwise present. The "action level" is defined as one-half of the recommended workplace exposure concentration designated as a ceiling limit for ethylene dibromide. Exposure to airborne ethylene dibromide at concentrations less than the action level, as determined in accordance with Section 8, will not require adherence to Sections 2, 3, $4(\mathrm{a})$, or $8(\mathrm{c}, \mathrm{d})$. If exposure to other chemicals also occurs, the employer shall comply with any applicable standard for the other chemicals.

Section 1 - Environmental (Workplace Air)

(a) Concentration

The employer shall control workplace concentrations of ethylene dibromide so that no employee is exposed in his workplace to concentrations greater than $1.0 \mathrm{mg} / \mathrm{cu} \mathrm{m}(0.13 \mathrm{ppm})$ as a ceiling limit, as determined by a sampling period of 15 minutes. 
(b) Sampling and Analysis

Procedures for the collection and analysis of workroom air samples for compliance with the standard shall be as provided in Appendices I and II, or by any methods shown to be at least equivalent in precision, sensitivity, and accuracy to the methods specified.

\section{Section 2 - Medical}

Medical surveillance shall be made available to employees as outlined below:

(a) Comprehensive preplacement and annual medical examinations unless a more frequent schedule is indicated by professional medical judgment based on such factors as emergencies, variations in work periods, and the preexisting health status of the individual worker.

(b) These examinations shall include at least:

(1) Comprehensive or interim medical and work histories, with special emphasis directed to disorders of the heart, liver, kidneys, and nervous system.

(2) A comprehensive physical examination, with particular emphasis given to cardiovascular, pulmonary, neurologic, hepatic, and renal systems, and to the skin.

(3) An evaluation of the employee's physical ability to safely wear a negative or positive pressure respirator.

(c) Employees shall be counseled by the physician to ensure that each employee is aware that ethylene dibromide has been shown to induce in experimental animals adverse effects in reproductive processes, including 
abnormalities in offspring, mutations, and stomach cancer following direct administration. The relevancy of these findings in animals to male or female employees has not yet been established. They do indicate, however, that both employers and employees should do everything possible to minimize exposures to ethylene dibromide. If a physician becomes aware of any adverse effects on the reproductive system, or cancers in individuals who have been exposed to ethylene dibromide, or any abnormal babies born to parents either or both of whom have been exposed to ethylene dibromide, such information should be forwarded to the Director, National Institute for Occupational Safety and Health, as promptly as possible.

(d) Medical attention shall be provided promptly to all employees suspected of being exposed to ethylene dibromide vapor at or above the action level or to liquid ethylene dibromide. A 48-hour medical observation period for delayed systemic or dermal effects is recommended.

(e) Examinations of current employees shall be performed as soon as practicable after the promulgation of a standard based on these recommendations.

(f) The employer shall maintain medical records for all persons exposed to ethylene dibromide at or above the action level. All medical records, Including information on required medical examinations and supporting documents, shall be kept for at least 30 years after the termination of the individual's employment.

(g) The medical representatives of the Secretary of Health, Education, and Welfare, of the Secretary of Labor, of the employee or former employee, and of the employer shall have access to these medical records. 
Section 3 - Labeling and Posting

All labels and warning signs shall be printed both in English and in the predominant language of non-English-reading workers. Illiterate workers and workers reading languages other than those used on labels and posted signs shall receive information regarding hazardous areas and shall be informed of the instructions printed on labels and signs.

(a) Labeling

The following warning label shall be affixed in a readily visible location on ethylene dibromide processing or other equipment and on ethylene dibromide storage tanks or containers:

\section{ETHYLENE DIBROMIDE}

WARNING!!

CANCER-SUSPECT AGENT

BREATHING VAPOR MAY BE HAZARDOUS TO HEALTH

CAN BE FATAL IF SWALLOWED

HARMFUL IF ABSORBED THROUGH SKIN

CAUSES SEVERE IRRITATION OF SKIN AND EYES

Avold breathing vapor.

Avoid contact with skin or eyes.

Use only with adequate ventilation.

Keep containers closed when not in use.

Wash thoroughly before eating, drinking, smoking, or using tollet.

First ald: If inhaled, remove to fresh air. Give artificial respiration if needed. Give oxygen if breathing is impaired. Call a physician.

In case of contact, immediately flush eyes or skin with water for at least 15 minutes. Call a physician.

If swallowed, induce vomiting immediately if patient is consclous. Call a physician. 


\title{
(b) Posting
}

Areas in which ethylene dibromide is present shall be posted with a sign reading:

ETHYLENE DIBROMIDE

\author{
WARNING! CANCER-SUSPECT AGENT \\ HARMFUL IF INHALED \\ CAN BE FATAL IF SWALLOWED \\ HIGHLY IRRITATING TO SKIN AND EYES \\ HARMFUL IF ABSORBED THROUGH SKIN
}

Section 4 - Personal Protective Equipment and Clothing

(a) Respiratory Protection

(1) Engineering controls shall be used wherever needed to keep airborne ethylene dibromide concentrations below the recomended occupational exposure limit. Compliance with this limit may be achieved by the use of respirators under the following conditions only:

(A) During the time necessary to install or test the required engineering controls.

(B) For nonroutine operations, such as emergency maintenance or repair activities.

(C) During emergencies when air concentrations of ethylene dibromide may exceed the recommended occupational exposure limit.

(2) When a respirator is permitted by paragraph (a) (1) of this section, it shall be selected and used pursuant to the following requirements : 
(A) The employer shall ensure that no employee is exposed to ethylene dibromide because of improper respirator selection, fit, use, or maintenance.

(B) The employer shall establish and enforce a respirator program meeting the requirements of 29 CFR 1910.134 as amended. (C) The employer shall provide respirators in accordance with Table I-1 and shall ensure that the employee uses the respirator provided when necessary.

(D) Respiratory protective devices described in Table I-1 shall be those approved under the provisions of 30 CFR 11 .

(E) Respirators specified for use in higher concentrations of ethylene dibromide may be used in atmospheres of lower concentrations.

(F) The employer shall ensure that chemical cartridges are not used with ethylene dibromide except for evacuation or escape because of the poor warning properties of ethylene dibromide at the recommended occupational exposure limit.

(G) The employer shall ensure that respirators are adequately cleaned and maintained, and that employees are instructed and drilled, at least annually, in the proper use and testing for leakage of respirators assigned to them.

(H) Respirators shall be easily accessible and employees shall be informed of their location. 
TABLE I-1

RESPIRATOR SELECTION GUIDE FOR ETHYLENE DIBROMIDE

\begin{tabular}{|c|c|}
\hline Concentration & $\begin{array}{l}\text { Respirator Type Approved } \\
\text { under Provisions of } 30 \mathrm{CFR} 11\end{array}$ \\
\hline $\begin{array}{l}\text { Less than or } \\
\text { equa1 to } \\
10 \mathrm{mg} / \mathrm{cu} \mathrm{m}\end{array}$ & $\begin{array}{l}\text { Supplied-air respirator with half-mask } \\
\text { facepiece operated in demand (positive } \\
\text { pressure) mode }\end{array}$ \\
\hline $\begin{array}{l}\text { Less than or } \\
\text { equal to } \\
50 \mathrm{mg} / \mathrm{cu} \mathrm{m}\end{array}$ & $\begin{array}{l}\text { (1) Supplied-air respirator with full } \\
\text { facepiece, helmet, or hood } \\
\text { (2) Self-contalned breathing appara- } \\
\text { tus with full facepiece }\end{array}$ \\
\hline $\begin{array}{l}\text { Less than or } \\
\text { equal to } \\
2,000 \mathrm{mg} / \mathrm{cu} \mathrm{m}\end{array}$ & $\begin{array}{l}\text { Type C supplied-air respirator with } \\
\text { full faceplece operated in pressure- } \\
\text { demand or other positive pressure mode } \\
\text { or with full facepiece, hood, or hel- } \\
\text { met operated in continuous-flow mode }\end{array}$ \\
\hline $\begin{array}{l}\text { Greater than } \\
2,000 \mathrm{mg} / \mathrm{cu} \mathrm{m} \\
\text { or entry into } \\
\text { area of unknown } \\
\text { concentration }\end{array}$ & $\begin{array}{l}\text { (1) Self-contained breathing appara- } \\
\text { tus with full facepiece operated in } \\
\text { pressure-demand or other positive } \\
\text { pressure mode } \\
\text { (2) Combination respirator that in- } \\
\text { cludes Type C supplied-air respirator } \\
\text { with full facepiece operated in pres- } \\
\text { sure-demand or other positive pressure } \\
\text { or continuous-flow mode and auxiliary } \\
\text { self-contained breathing apparatus op- } \\
\text { erated in pressure-demand or positive } \\
\text { pressure mode } \\
\text { (3) Supplied-air suits may be neces- } \\
\text { sary }\end{array}$ \\
\hline
\end{tabular}


(b) Eye Protection

Eye protective devices shall be provided by the employer and used by each employee where contact of ethylene dibromide with the eyes is likely. Chemical safety goggles or plastic face shields (8-inch minimum) with goggles made completely of ethylene dibromide-resistant materials shall be used. Selection, use, and maintenance of eye protective devices shall be in accordance with 29 CFR 1910.133.

\section{(c) Protective Clothing}

Protective clothing shall be resistant to the penetration and to the chemical action of ethylene dibromide. Additional protection, including gloves, bib-type aprons, boots, and overshoes, shall be provided for, and worn by, each employee while in any operation that may cause direct contact with liquid ethylene dibromide. Supplied-air hoods or suits resistant to penetration by ethylene dibromide shall be worn when entering confined spaces, such as pits or storage tanks. In situations where heat stress is likely to occur, supplied-air suits, preferably cooled, are recommended. The employer shall ensure that all personal protective clothing is inspected regularly for defects and is maintained in a clean and satisfactory condition by the employee.

\section{Section 5 - Informing Employees of Hazards from Ethylene Dibromide}

(a) Al1 new and present employees working where occupational exposure to ethylene dibromide may occur shall be informed orally and in writing of the hazards, relevant signs and symptoms of exposure, appropriate emergency procedures, and proper conditions and precautions concerning safe use and handling of ethylene dibromide. First-aid 
procedures shall be included. This information shall be readily available to all employees involved in the manufacture, use, transport, or storage of ethylene dibromide and shall be posted in prominent positions within the workplace.

(b) A11 employees involved with the manufacture, use, transport, or storage of ethylene dibromide shall be informed that ethylene dibromide has been reported to induce cancer in experimental animals after repeated oral intubation.

(c) Employers shall institute a continuing education program to ensure that a11 employees have current knowledge of job hazards, maintenance procedures, cleanup methods, emergency procedures, and evacuation procedures. This program should include at least:

Emergency procedures and drills.

Instruction in handling spills and leaks. Decontamination procedures. Location and use of firefighting equipment. First-aid procedures, equipment location, and use. Rescue procedures. Confined space entry procedures. Inadequacy of odor as a means of detection.

Records of such training should be kept for inspection by authorized personnel as required. This program shall be held for all employees with occupational exposure to ethylene dibromide at intervals not greater than quarterly, or whenever there is a process change.

(d) Information as required shall be recorded on the "Material Safety Data Sheet" shown in Appendix III, or on a similar form approved by the Occupational Safety and Health Administration, US Department of Labor. 
Section 6 - Work Practices

(a) Emergency Procedures

For all work areas where emergencies may occur, the employer shall take all necessary steps to ensure that employees are instructed in and follow the procedures specified below and any others appropriate to the specific operation or process.

(1) Procedures shall include at least prearranged plans for:

(A) Immediate evacuation, transportation, and medical assistance for affected employees; this procedure should include alerting medical treatment facilities of the impending arrival of affected employees.

(B) Designation of medical receiving facilities and names of physicians trained in ethylene dibromide emergency procedures.

(C) Reentry into areas where ethylene dibromide leaks or spills have occurred for cleanup, decontamination, or maintenance purposes.

(2) Evacuation alarm systems shall be provided by the employer.

(3) Personal protective equipment and clothing as specified in Section 4 shall be used by trained personnel essential to emergency operations.

(4) Nonessential employees shall be evacuated from hazardous areas during emergencles. Perimeters of these areas shall be delineated, posted, and secured. The employees in adjacent areas shall be trained in evacuation procedures if these work areas become involved. 
(5) Only personnel trained in the emergency procedures and protected against the attendant hazards shall shut off sources of ethylene dibromide, clean up spills, control and repair leaks, and fight fires in ethylene dibromide areas.

(6) Firefighting procedures shall be established for areas where flammable materials are used with ethylene dibromide. Chemical foam, carbon dioxide, or dry chemicals shall be used for fighting fires in areas where ethylene dibromide is present. Proper protective respirators and clothing shall be worn by all personnel in the hazard area until concentrations of airborne ethylene dibromide have been demonstrated by monitoring to be below the recommended occupational exposure limit.

(7) Showers, eyewash fountains, and washroom facilities shall be provided and so located as to be readily accessible to workers in all areas where skin or eye contact with liquid ethylene dibromide is likely. If liquid ethylene dibromide is splashed on the clothing or skin, contaminated clothing shall be promptly removed and the skin washed thoroughly with soap and water for at least 15 minutes. If liquid ethylene dibromide gets into the eyes, they shall be irrigated immediately with coplous quantities of running water for at least 15 minutes.

(8) Medical attention shall be provided promptly for any affected worker. Such exposures shall be reported to the immediate supervisor by the affected worker or by a fellow employee.

(b) Control of Airborne Ethylene Dibromide

(1) Suitable engineering controls designed to limit exposure to ethylene dibromide to that prescribed in Section $1(a)$ shall be used. The use of completely enclosed processes is the recommended method 
of control for ethylene dibromide. Local exhaust ventilation may also be effective, used alone or in combination with process enclosure. When a local exhaust ventilation system is used, it shall be designed to prevent the accumulation or recirculation of ventilation control or process air in the workroom, to maintain ethylene dibromide concentrations below the limit of the recommended standard, and to remove ethylene dibromide from the breathing zones of employees. Exhaust systems discharging into outside air must conform with applicable local, state, and federal air pollution regulations. Ventilation systems shall be subjected to regular preventive maintenance and cleaning to ensure effectiveness, which shall be verified by periodic airflow measurements at least every 3 months. Measurements of system efficiency shall also be made immediately by personnel properly attired in specified protective equipment when any change in production, process, or control might result in increased concentrations of airborne ethylene dibromide. Tempered makeup air shall be provided to work areas in which exhaust ventilation is operating.

(2) Forced-draft ventilation systems shall be equipped with remote manual controls and sha1l be designed to turn off automatically in the event of a fire in the work area.

(c) Handling of Ethylene Dibromide and General Work Practices (1) Written operating instructions and emergency medical procedures shall be formulated and posted where ethylene dibromide is handled or used.

(2) Prompt medical attention shall be provided if there is known or suspected exposure to ethylene dibromide, whether or not symptoms are present. 
(3) The employer shall ensure that safety showers, eyewash fountains, and other emergency equipment is in proper working order through regularly scheduled inspections performed by qualified maintenance personne1.

(4) Ethylene dibromide operating systems sha11 be inspected daily for signs of leaks by personnel attired in specified protective equipment. All equipment including valves, fittings, and connections shall be checked for tightness and good working order. A1l newly made connections shall be checked for leaks immediately after ethylene dibromide is introduced by trained personnel attired in prescribed personal protective equipment.

(5) If there is a leak, the leak shall be corrected immediately. Work shall resume normally only after necessary repair or replacement has been completed, the area has been vent1lated, and the concentration of ethylene dibromide has been determined by monitoring to be below the recommended occupational exposure limit.

(6) Transportation and use of ethylene dibromide shall comply with all applicable local, state, and federal regulations. Where ethylene dibromide is used as a fumigant, strict adherence to the pesticide container label requirements for application and personal protection shall be followed. Additional standards for pesticide use by agricultural workers can be found in 40 CFR 170.

(7) When ethylene dibromide containers are being moved, or when they are not in use and are disconnected, valve protection covers shall be in place. Containers shall be moved only with the proper 
equipment and shall be secured to prevent dropping or loss of control while moving.

(8) Process valves and pumps shall be readily accessible and should not be located in pits and congested areas.

(9) Containers and systems shall be handled and opened with care. Approved protective equipment as specified in Section 4 shall be worn while opening, connecting, and disconnecting ethylene dibromide contalners and systems. Adequate ventilation shall be available to prevent exposure to ethylene dibromide when opening containers and systems.

(10) Personnel shall work in teams when ethylene dibromide is first admitted to a system, while repairing leaks, or when entering a confined or enclosed space.

(11) Any odor of ethylene dibromide shall be reported to a responsible authority and an alarm sounded immediately.

(d) Work Areas

(1) Ethylene Dibromide Hazard Areas

A hazard area shall be considered as any space workers may enter that has physical characteristics and sources of ethylene dibromide that could result in air concentrations exceeding the recommended limit. Exits sha1l be plainly marked and shall open outward. Emergency exit doors shall be conveniently located and shall open into areas which will remain free of contamination in an emergency. At least two separate means of exit shall be provided from each room or building in which ethylene dibromide is stored, handled, or used in quantities that could create a hazard. 
(2) Confined or Enclosed Spaces

Entry into confined spaces, such as tanks, pits, process

vessels, tank cars, sewers, or tunnels, where there may be limited egress shall be controlled by a permit system. Permits shall be signed by an authorized employer representative certifying that preventive and protective measures have been followed.

Confined spaces which have contained ethylene dibromide sha11 be thoroughly ventilated to ensure an adequate supply of oxygen, tested for ethylene dibromide and other contaminants, and inspected for compliance with these requirements prior to each entry. Adequate ventilation shall be maintained while workers are in the space. Leakage of ethylene dibromide into the confined space while work is in progress shall be prevented by disconnecting and blanking the ethylene dibromide supply lines. An individual enterlng confined spaces shall be furnished with appropriate personal protective equipment and protected by a lifeline harness tended by another worker outside the space, who shall also be equipped for entry with approved personal protective equipment and who has contact with a third party. Communication (visual, voice, signal line, telephone, radio, or other suitable means) shall be maintained by the standby person with the employee inside the confined or enclosed space. A third employee, equipped to proceed to the aid of the other two if necessary, shall have general surveillance of their activities.

(e) Storage

(1) Storage facilities shall be designed to contain spills completely within a surrounding dike and to prevent contamination of workroom air. 
(2) Storage of ethylene dibromide in the same area as reactive metals, such as aluminum or magnesium, or as liquid ammonia shall be prohibited.

(3) Ethylene dibromide sha11 be stored in tightly closed containers in a well-ventilated area away from excessive heat and sunlight.

(4) Storage containers shall be periodically inspected for leakage.

(5) Ventilation switches and emergency respiratory equipment shall be located outside storage areas in readily accessible locations which will be free of ethylene dibromide in an emergency.

(f) Spills, Leaks, and Waste D1sposal

(1) If ethylene dibromide leaks or is spilled, the following steps shall be taken:

(A) Evacuate all nonessential personnel from the area.

(B) Adequately ventilate the area of the spill or leak to prevent accumulation of the vapor.

(C) If in liquid form, collect spilled material for reclamation or absorb in vermiculite, dry sand, earth, or similar nonreactive material.

(D) If in solid form, collect spilled material in the most convenient and safe manner for reclamation or for disposal.

(2) Personnel entering the spill or leak area shall be furnished with appropriate personal protective equipment. All other personnel shall be excluded from the area. 
(3) All wastes and residues containing ethylene dibromide shall be collected in ethylene dibromide-resistant containers and incinerated or buried in such a manner that no ethylene dibromide or toxic decomposition products are released to the environment.

\section{Section 7 - Sanitation Practices}

(a) Plant sanitation shall meet the requirements of 29 CFR 1910.141.

(b) Appropriate locker rooms shall be available for changing into required protective clothing in accordance with 29 CFR 1910.141(e). Clothing contaminated with liquid ethylene dibromide shall be immediately removed and placed in a closed container in a well-ventilated area for later disposal or decontamination. Employers shall require personnel who work with ethylene dibromide to shower before leaving the workplace at the end of a workday.

(c) Employers shall ensure that employees who handle ethylene dibromide wash their hands thoroughly with soap and water before eating, smoking, or using toilet facilities.

(d) The storage, dispensing, preparation, and consumption of food, beverages, or tobacco shall be prohibited in ethylene dibromide work areas.

(e) The employer shall ensure that personnel who launder and clean clothing or equipment contaminated with ethylene dibromide are provided adequate personal protective equipment to prevent exposure and shall ensure that these employees are aware of the potential hazards of exposure to ethylene dibromide. 
Section 8 - Monitoring and Recordkeeping Requirements

(a) Industrial hygiene surveys shall be made in any workplace where ethylene dibromide is handled, processed, or stored. Records of these surveys, including the basis for concluding that environmental concentrations are below the recommended limit or below the action level, shall be maintained. Surveys shall be repeated every month or whenever a process change is made.

(b) Where exposure concentrations have not been determined, they shall be determined as soon as practicable after the promulgation of a standard based on these recommendations.

(c) Requirements set forth below apply to work areas in which the concentration of ethylene dibromide has been determined to be at or above the action level.

(1) An adequate number of samples shall be collected monthly in accordance with Appendix I for the evaluation of the work environment with respect to the occupational exposure of the employees.

(2) Environmental samples shall be taken when a new process is installed or process changes are made which may cause an increase in environmental concentrations. Significantly increased production, relocation of existing operations, interruption of normal maintenance schedules, or other functions which may increase ethylene dibromide concentrations shall require resampling and analysis.

(3) In all monitoring, samples shall be collected in accordance with the provisions prescribed in Section $1(b)$.

(4) The minimum number of representative exposure determinations for an operation or process shall be based on variations in 
exposures and production schedules and in accordance with the provisions prescribed in Section $1(\mathrm{~b})$.

(5) If initial, periodic, or special evaluations indicate that the recommended limit is exceeded, corrective engineering or other control measures shall be immediately instituted to ensure the safety of employees until a concentration below the recommended occupational exposure limit is achieved. In such cases, sampling of each operation and work location shall be conducted at least weekly until two consecutive employee exposure measurements, taken at least 1 week apart, reveal that the employee is not exposed to ethylene dibromide above the recommended occupational exposure limit. Employers shall notify in writing, within 5 days, every employee who is found to be exposed to ethylene dibromide above the recommended environmental limit.

(d) Employers or their successors shall maintain records which shall include sampling and analytical methods, types of respiratory protection used, concentrations found, and information concerning exposure of employees to ethylene dibromide. Each employee shall have access to data on the employee's own environmental exposures. Pertinent records of occupational accidents and environmental exposures within the workplace shall be kept for at least 30 years after the worker's employment has ended. Records of occupational exposures applicable to an employee should be included in that employee's medical records. The medical representatives of the Secretary of Health, Education, and Welfare, of the Secretary of Labor, of the employee or former employee, and of the employer shall have access to all such records. 


\section{INTRODUCTION}

This report presents the criteria and the recommended standard which were prepared to meet the need for preventing disease or injury arising from exposure to ethylene dibromide. The criteria document fulfills the responsibility of the Secretary of Health, Education, and Welfare under Section $20(a)(3)$ of the Occupational Safety and Health Act of 1970 to "...develop criteria dealing with toxic materials and harmful physical agents and substances which will describe...exposure levels at which no employee will suffer impalred health or functional capacities or diminished Iife expectancy as a result of his work experience."

The National Institute for Occupational Safety and Health (NIOSH), after a review of data and consultation with others, has formalized a system for the development of criteria upon which standards can be established to protect the health and provide for the safety of employees exposed to hazardous chemical and physical agents. Any criteria and recommended standard should enable management and labor to develop better engineering controls and more healthful work practices. Simple compliance with the recommended standard should not be used as a final goal.

These criteria for a standard for ethylene dibromide are part of a continuing series of documents developed by NIOSH. The recommended standard applies to the processing, manufacture, use of, or other occupational exposure to ethylene dibromide as applicable under the Occupational Safety and Health Act of 1970. The standard was not designed for the population-at-large, and any extrapolation beyond occupational exposures is not warranted. It is intended to (1) protect against the 
development of short- and long-term adverse effects on health from ethylene dibromide exposure, (2) protect against local effects on the skin, (3) be measurable by techniques that are valid, reproducible, and available to industry and government agencies, and (4) be attainable with existing technology.

The development of the criteria for the recommended standard for occupational exposure to ethylene dibromide has demonstrated a need for further research in the following areas: (1) epidemiologic studies of employees exposed to ethylene dibromide, (2) animal studies designed to determine the cumulative effects from dermal contact and inhalation of ethylene dibromide, (3) studies on the mutagenic effects of ethylene dibromide in mammals, and (4) animal studies to investigate the carcinogenic and reproductive effects from ethylene dibromide by dermal absorption and inhalation.

Adherence to the recommended standard for occupational exposure to ethylene dibromide is intended to minimize the potentials for the induction of sterility, carcinogenesis, mutagenesis, or teratogenesis in employees and their offspring from exposure to ethylene dibromide in the workplace. Adherence to the recommended standard is also intended to minimize the hazards from skin penetration and irritation associated with exposure to liquid ethylene dibromide and the delayed and insidious long-term systemic effects resulting from exposure to both liquid and vaporous ethylene dibromide. 